\title{
Is there Unity in Europe? First Survey of EUPSA Delegates on the Management of Gastroschisis
}

\author{
Augusto Zani ${ }^{1}$ Elke Ruttenstock ${ }^{2}$ Mark Davenport ${ }^{1}$ Niyi Ade-Ajayi ${ }^{1}$ \\ ${ }^{1}$ Department of Paediatric Surgery, King's College Hospital, London, \\ United Kingdom \\ 2 Department of Pediatric and Adolescents Surgery, Medical University \\ of Graz, Styria, Austria \\ Address for correspondence and reprint requests Augusto Zani, MD, \\ MRCS, Department of Paediatric Surgery, King's College Hospital, \\ Denmark Hill, London SE5 9RS, United Kingdom \\ (e-mail: a.zani@ich.ucl.ac.uk).
}

Eur J Pediatr Surg 2013;23:19-24.

\begin{abstract}
Keywords

- abdominal wall defect

- preformed silo

- intestinal atresia

- Bianchi

Aim To report the first European survey on the current management of gastroschisis and ascertain the degree of variability between centers.

Methods A 10-question survey was administered at the 2011 European Paediatric Surgeons' Association (EUPSA) Congress. Questionnaires were completed by 205 delegates from 39 countries. A total of 21 responses (10\%) were incomplete and voided. The remaining 184 were divided on the basis of following region of practice: Western Europe (WE, $n=102$ ), Eastern Europe (EE, $n=59$ ), and non-European countries $(n=23)$. Differences between WE and EE were analyzed using contingency tests. $p<0.05$ was considered significant.

Results A total of $15 \%$ WE and $2 \%$ EE responders work in centers where antenatal magnetic resonance imaging scans are routinely used. Nonplanned delivery is the most popular approach (WE 46\%, EE 58\%). Primary closure is the preferred choice (WE 92\%, EE $86 \%$ ), and it is achieved by operative fascial closure in the majority (WE $80 \%$, EE 75\%) rather than by Bianchi technique (WE 20\%, EE 25\%). Staged reduction and closure is less popular (WE 8\%, EE 14\%), and it is achieved by custom-made silo (WE 25\%, EE 12.5\%), preformed silo (PFS) followed by surgical closure (WE 63\%, EE 75\%), or PFS followed by sutureless closure (WE 12\%, EE 12.5\%). Objection to PFS in WE is mainly related to surgeons' lack of confidence in the technique (40\%), whereas in EE it is due to unavailability and high cost $(62 \%, p=0.01)$. In case of associated intestinal atresia, immediate resection and anastomosis is preferred by $60 \%$ of WE surgeons versus $35 \%$ of EE surgeons ( $p=0.03$ ), who equally favor primary closure and delayed surgery $(33 \%)$. Nutrition is preferably delivered by peripheral long line in WE (64\%) and by central line inserted in the first week of life in $\mathrm{EE}(62 \%, p=0.003)$.

Conclusions Primary fascial closure is currently the preferred method of gastroschisis closure across Europe. Aspects of care such as strategy for intestinal atresia and delivery of parenteral nutrition differ significantly between WE and EE. Economic considerations appear to influence management strategy particularly in EE. A Europe-wide audit appears warranted to identify whether this survey reflects actual practice.
\end{abstract}

received

May 17, 2012

accepted after revision

July 18, 2012

published online

October 23, 2012 (c) 2013 Georg Thieme Verlag KG

Stuttgart · New York
DOI http://dx.doi.org/ $10.1055 / \mathrm{s}-0032-1326954$. ISSN 0939-7248. 


\section{Introduction}

Although the medical and surgical strategies for infants with gastroschisis have evolved considerably in recent decades, optimal management has yet to be determined. Several options for prenatal, preoperative, operative, and postoperative care are available, but little consensus has been reached yet.

There have been few randomized controlled trials investigating aspects of the management of gastroschisis. ${ }^{1-3}$ In 2004, a United Kingdom-based double-blind placebo-controlled trial demonstrated that erythromycin was not effective in the management of gastrointestinal dysmotility following primary repair of uncomplicated gastroschisis. ${ }^{1}$ In 2005, another United Kingdom-based randomized trial showed no significant benefit from elective preterm delivery of fetuses with gastroschisis. ${ }^{2}$ In 2008, a North American trial studied the randomized use of spring-loaded silos in simple gastroschisis and showed that this was as safe as primary closure. $^{3}$

The British Association of Pediatric Surgeons-Congenital Anomalies Surveillance System (BAPS-CASS) conducted a national audit of gastroschisis in all pediatric surgical units between 2006 and 2008. ${ }^{4}$ This provided a comprehensive picture of current United Kingdom practice in the surgical management of gastroschisis, and demonstrated better shortterm outcomes for infants with simple gastroschisis compared with complex cases. ${ }^{4}$

With the similar aim to define the practice patterns in the management of gastroschisis in North America, an electronic survey was sent to all second-year residents in accredited pediatric surgery programs in the United States and Canada. ${ }^{5}$ This survey demonstrated that in North-America, there is a great variability in the care of infants with gastroschisis between institutions, as well as among faculty within single programs, and that protocol-driven care for this condition is rare. $^{5}$

There have been two recent surveys of current surgical practice in the United Kingdom and North America, ${ }^{4,5}$ but to date there is no comparable study of practice in Europe. The aim of this study was to define the spectrum of management of gastroschisis in Europe, and to ascertain the degree of variability among surgical centers.

\section{Methods}

A questionnaire was supplied to all delegates attending the 12th European Congress of Pediatric Surgery (Barcelona, 15 to 18 June 2011) and collected on the last day of the conference.

Respondents were asked to fill in their position (Head of Department/Permanent Staff or Consultant/Trainee), hospital, and country of practice. Questions included nature of prenatal and postnatal management, as well as controversial issues, such as management of associated intestinal atresia, delivery of nutrition, and management of persistent intestinal dysmotility ( $\rightarrow$ Table 1 ).

Questionnaires were completed by 205 delegates, including 38 heads of department, 96 consultants, 44 trainees, and 3 medical students. On 24 questionnaires, the respondent did not disclose his/her grade. A total of 161 respondents were from 25 European countries, and 23 from 14 non-European countries ( - Table 2 ). A total of 21 responses (10\%) were incomplete and declared void. The remaining 184 questionnaires were divided on the basis of the following region of practice: Western Europe (WE, $n=102$ ), Eastern Europe (EE, $n=59)$, and non-European countries $(n=23)$. For the purpose of this study, questionnaires from non-European countries were not included in the analysis.

Differences between WE and EE were analyzed using contingency tests. $p<0.05$ was considered significant. For figures, the y-axix represent the proportion of respondents for each question.

\section{Results}

Of the 161 European respondents, 35 (22\%; WE, $n=18,18 \%$; $\mathrm{EE}, n=17,29 \%)$ were head of departments, 78 (48\%; WE, $n=52,51 \%$; EE, $n=26,44 \%$ ) were consultants, 43 (27\%; WE, $n=30,29 \%$; EE, $n=13,22 \%)$ were trainees, and 3 (2\%; WE, $n=1,1 \%$; EE, $n=2,3 \%)$ were medical students. On two (1\%; $\mathrm{WE}, n=1,1 \%$;E, $n=1,2 \%$ ) questionnaires, the respondents did not disclose their grade.

The number of gastroschisis infants treated per year per center in WE and EE is similar ( - Fig. 1A). In fact, 45 (44\%) WE and 19 (32\%) EE respondents reported working in a center that treats $<5$ patients with gastroschisis a year, 40 (39\%) WE and 31 (53\%) EE treat 5 to 10 infants per year, and 17 (17\%) WE and $9(15 \%)$ EE treat $>10$ infants per year ( - Fig. 1A).

Delivery of a gastroschisis baby is not planned in the majority of WE $(n=47,46 \%)$ and $\mathrm{EE}(n=34,58 \%)$ centers (-Fig. 1B). However, 16 (16\%) WE and 3 (5\%) EE centers plan delivery at 34 weeks of gestation; $26 \mathrm{WE}(25 \%)$ and $12(20 \%)$ EE at 36, and $11(11 \%) \mathrm{WE}$ and $10(17 \%)$ EE at 38 (-Fig. 1B). Moreover, two (2\%) WE centers plan elective delivery at 37 weeks of gestation.

Antenatal magnetic resonance imaging (MRI) scans are never performed according to 23 (23\%) WE and 23 (39\%) EE respondents, are occasionally used in 63 (62\%) WE and 35 (59\%) EE centers, and are routinely performed in 16 (15\%) WE and $1(2 \%)$ EE centers ( - Fig. 1C).

Primary closure is the preferred choice in an infant with simple gastroschisis in the vast majority of both $\mathrm{WE}$ ( $n=94$, $92 \%)$ and $\mathrm{EE}(n=51,86 \%)$ centers. Primary closure is most commonly achieved by operative fascial closure both in WE $(n=75,80 \%)$ and in EE $(n=38,75 \%)$ centers ( - Fig. $2 A)$. Conversely, cot-side reduction and closure, also known as Bianchi technique, ${ }^{6}$ was reported by 19 WE (20\%) and 13 (25\%) EE respondents ( - Fig. 2A).

Staged reduction and closure for simple gastroschisis is less popular both in WE $(n=8,8 \%)$ and in $\mathrm{EE}(n=8,14 \%)$. Staged reduction and closure is most commonly achieved by preformed silo (PFS) followed by surgical closure in five WE (63\%) and 6 (75\%) EE centers ( - Fig. 2B). Less popular are the use of the custom-made silo, reported by 2 (25\%) WE and 1 (12.5\%) EE respondents, and the use of PFS followed by sutureless closure, reported by 1 (12\%) WE and $1(12.5 \%)$ EE respondents (-Fig. 2B). 
Table 1 The 10-question paper questionnaire administered to delegates of the 2011 EUPSA Congress

\begin{tabular}{|c|c|}
\hline 1. & $\begin{array}{l}\text { Question: How many patients with gastroschisis does your center treat per year? } \\
\text { Answer: }<5 / 5-10 />10\end{array}$ \\
\hline 2. & $\begin{array}{l}\text { Question: In your center, are gastroschisis babies routinely delivered early in the absence of antenatal intestinal } \\
\quad \text { anomalies or obstetric indications? } \\
\text { Answer: No/Yes, at } 34 \text { weeks of gestation/Yes, at } 36 \text { weeks of gestation/Yes, at } 38 \text { weeks of gestation }\end{array}$ \\
\hline 3. & $\begin{array}{l}\text { Question: In your center, is antenatal MRI scan used? } \\
\text { Answer: Never/occasionally/routinely }\end{array}$ \\
\hline 4. & $\begin{array}{l}\text { Question: In a baby with simple gastroschisis, what is usually your initial approach? } \\
\text { Answer: A - Primary closure (custom-made silo only if necessary)/B - Staged reduction and closure }\end{array}$ \\
\hline 5. & $\begin{array}{l}\text { Question: If your approach is A (if primary closure possible), how do you achieve it? } \\
\text { Answer: Operative reduction with sutured fascial defect closure/Cot-side reduction and closure (Bianchi) }\end{array}$ \\
\hline 6. & $\begin{array}{l}\text { Question: If your approach is B, how do you achieve it? } \\
\text { Answer: Custom-made silo/preformed silo followed by surgical closure/preformed silo followed by sutureless } \\
\text { closure }\end{array}$ \\
\hline 7. & $\begin{array}{l}\text { Question: If you don't use the preformed silo, what is your main objection to its use? } \\
\text { Answer: Bad experience in the past/no previous experience/not available } \\
\text { Not convinced the preformed silo is better/too expensive/objection from other team member } \\
\text { (e.g., neonatologists)/other (please specify) }\end{array}$ \\
\hline 8. & $\begin{array}{l}\text { Question: If there is an associated intestinal atresia, what is your management? } \\
\text { Answer: Immediate enterostomy/immediate resection and primary anastomosis (if safe)/primary closure of } \\
\text { gastroschisis then delayed laparotomy/staged reduction and resection-anastomosis at closure/staged } \\
\text { reduction and enterostomy at closure/other (please specify) }\end{array}$ \\
\hline 9. & $\begin{array}{l}\text { Question: How do you usually deliver nutrition after gastroschisis closure? } \\
\text { Answer: Peripheral long line inserted on neonatal unit/surgically inserted central venous line (inserted in the first } \\
\text { week)/surgically inserted central venous line (inserted after the first week) }\end{array}$ \\
\hline 10. & $\begin{array}{l}\text { Question: What is your management of persistent gastroschisis-associated intestinal dysmotility at 2-3 months of } \\
\text { age? } \\
\text { Answer: Conservative/Domperidone/Erythromycin/Glycerine suppositories/therapeutic intestinal contrast } \\
\text { (e.g., Gastrografin)/rectal washouts/stoma formation/other (please specify) }\end{array}$ \\
\hline
\end{tabular}

Abbreviation: MRI, magnetic resonance imaging.

Objection to PFS in WE is mainly related to surgeons' lack of confidence in the technique (40\%), whereas in EE it is due to unavailability and high cost $(62 \%, p=0.01)$. Moreover, 8 (15\%) WE and 6 (21\%) EE reported no experience, whereas, only 3 out of the 84 respondents ( $1 \mathrm{WE}$ and $2 \mathrm{EE}$ ) declared a bad experience with the PFS.

Immediate resection and anastomosis in those with associated intestinal atresia is preferred by $48(60 \%)$ of WE surgeons versus $18(35 \%)$ of EE surgeons $(p=0.03)$, who equally favor primary closure and delayed surgery $(n=17$, 33\%, -Fig. 3A).

Nutrition is preferably delivered by peripheral long line in $\mathrm{WE}(n=58,64 \%)$ and by central line inserted in the first week of life in $\mathrm{EE}(n=34,62 \%, p=0.003$, - Fig. 3B). The practice of surgically inserting a central venous line after the first week of life has been reported only by 1 (2\%) EE respondents (-Fig. 3B).

Overall, the preferred methods of managing persistent gastroschisis-associated intestinal dysmotility at 2 to 3 months of age are rectal washouts ( $n=69,48 \%$ ), contrast enema ( $n=52,36 \%$ ), and erythromycin ( $n=42,29 \%)$. Conservative management was reported by 33 (23\%) surgeons, Domperidone administration by 29 (20\%), stoma creation by 27 (19\%), whereas glycerine suppositories are prescribed only by $10(7 \%)$.

\section{Discussion}

This appears to be the first Europe wide survey on the management of gastroschisis. The 2011 European Paediatric Surgeons' Association (EUPSA) Congress in Barcelona was an international meeting as shown by return of our questionnaires by delegates from 39 countries. Moreover, the meeting demonstrated the effectiveness of the association in facilitating the attendance of delegates from all countries of Europe. The focus of analysis on European practice reflects the success and the paucity of non-European delegates per country. The separation of Europe into western and eastern components, allowed the analysis of contemporary differences in practice with a historical backdrop.

In $\mathrm{WE}$, most of the respondents work in centers that treat $<5$ gastroschisis infants a year, whereas respondents from EE work in higher volume centers. This difference might reflect the different number of pediatric surgical centers per country in the two sides of Europe.

The majority of centers in Europe do not plan elective deliveries of those with an antenatal diagnosis in an attempt to reduce bowel exposure to potentially irritant amniotic fluid. ${ }^{2}$ This approach is supported by several studies that have shown that prematurity does not confer an advantage in restitution of gastrointestinal function in infants with 
22 Survey of EUPSA on the Management of Gastroschisis Zani et al.

Table 2 Respondents to the European gastroschisis survey distributed for country of origin and grouped on the basis of the region of practice in Western Europe, Eastern Europe, and non-European countries

\begin{tabular}{|l|l|l|l|l|l|}
\hline Western Europe & & Eastern Europe & & Non-European Countries \\
\hline Spain & 25 & Poland & 16 & Saudi Arabia & 5 \\
\hline Italy & 19 & Turkey & 15 & Mexico & 3 \\
\hline Germany & 12 & Romania & 11 & Canada & 2 \\
\hline UK & 9 & Russia & 6 & Thailand & 2 \\
\hline France & 8 & Serbia & 4 & USA & 2 \\
\hline The Netherlands & 6 & Latvia & 2 & Afghanistan & 1 \\
\hline Greece & 5 & Bulgaria & 1 & Australia & 1 \\
\hline Portugal & 5 & Hungary & 1 & Colombia & Costa Rica \\
\hline Austria & 3 & Slovak Republic & 1 & Egypt & 1 \\
\hline Denmark & 3 & Slovenia & 1 & Iran & 1 \\
\hline Sweden & 3 & Ukraine & & Israel & 1 \\
\hline Switzerland & 2 & & & Japan & Kuwait \\
\hline Belgium & 1 & & & Total & 1 \\
\hline Finland & 1 & 102 & Total & & 23 \\
\hline Total & & & & 1 \\
\hline
\end{tabular}

Abbreviation: UK, United Kingdom.
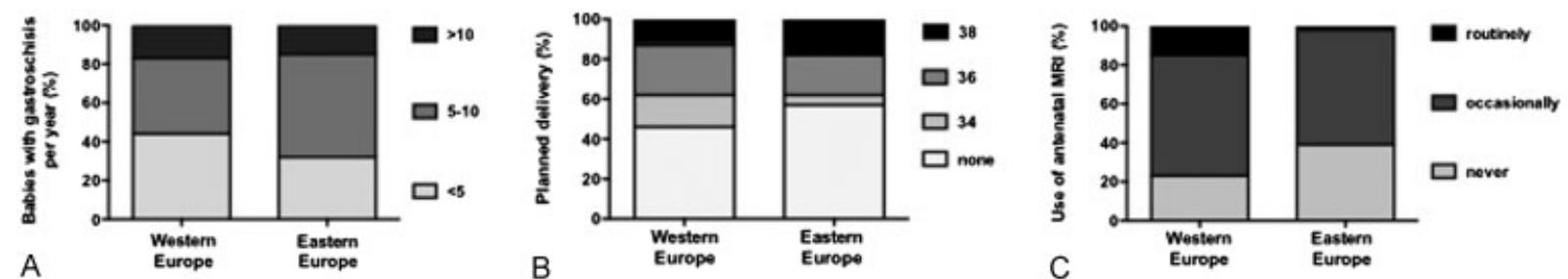

Figure 1 (A) Number of babies with gastroschisis treated per center per year (question 1); (B) time of delivery for gastroschisis fetuses (question 2); (C) use of magnetic resonance imaging (MRI) scans (question 3).
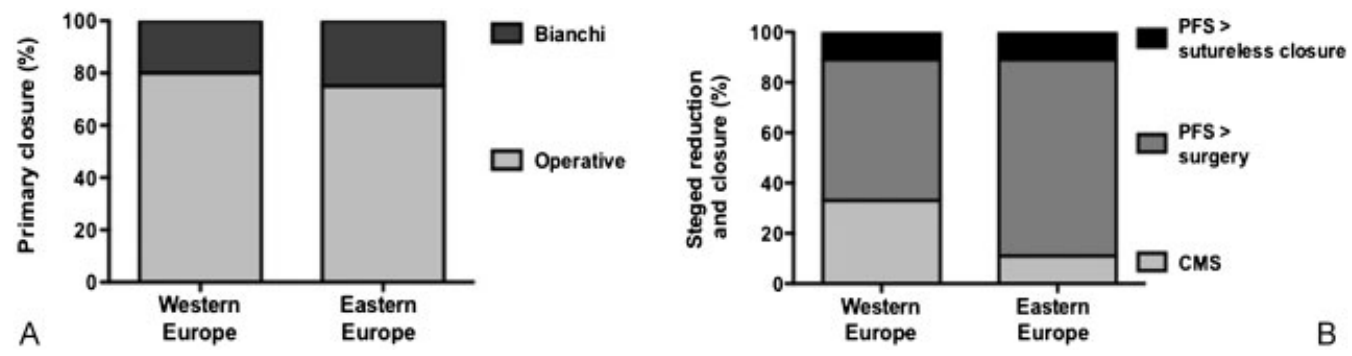

Figure 2 (A) Strategies of primary closure of simple gastroschisis (question 5); (B) Strategies of staged reduction and closure of simple gastroschisis (question 6).
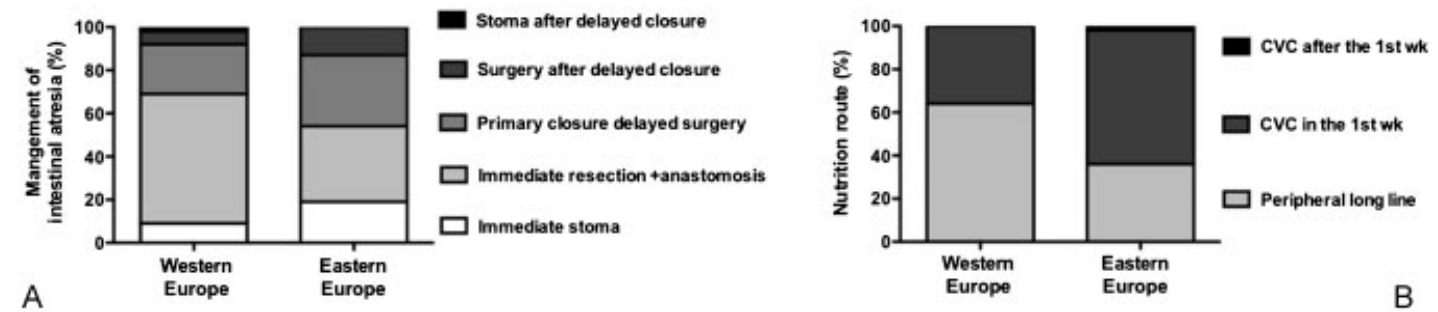

Figure 3 (A) Management of gastroschisis-associated intestinal atresia (question 8); (B) options for nutrition delivery following gastroschisis closure (question 9). 
gastroschisis, ${ }^{7-9}$ and confirmed by a RCT that showed no significant benefit in early elective delivery at 36 weeks of gestation. $^{2}$

The majority of WE and EE centers are concordant with the occasional use of antenatal MRI scans. This response mirrors the current paucity of literature on antenatal MRI for fetuses with gastroschisis and the lack of precise indications for its use. $^{10,11}$

Primary closure is currently the preferred method of gastroschisis closure across Europe (90\%). This is somewhat higher than the reported experience in both North America and the United Kingdom, where 76 and 58\%, respectively, attempted primary closure when feasible., ${ }^{4,5}$ The overall majority of respondents (78\%) to our survey declared a preference for operative fascial closure, which is similar to the approach chosen in $87 \%$ of the patients recorded by the BAPS-CASS audit. ${ }^{4}$ The type of primary closure was not one of the questions of the North American survey. ${ }^{5}$ The Bianchi technique was not popular in our study (overall 22\%), and even less performed (13\%) on the patients reported by the BAPS-CASS audit. ${ }^{4}$

Our survey showed that staged closure is not popular across Europe. In particular, the use of a PFS followed either by surgery or by sutureless closure was reported only by 13 respondents (8\%). Conversely, 22\% of the North American trainees favored the use of a silo. ${ }^{5}$ In the BAPS-CASS audit, $42 \%$ of neonates with simple gastroschisis underwent a staged closure, and a PFS was used in 120 out of all 336 neonates reported in the study. ${ }^{4}$ Comparisons of these studies are difficult to be made especially because surveys declare the expression of intentions, whereas audits report data on treated patients. Nonetheless, the use of PFS seems to be more popular in the United Kingdom than in the rest of Europe, as reported not only by the BAPS-CASS audit, ${ }^{4}$ but also by 4 (44\%) out of the 9 United Kingdom respondents to our survey. Surgeons across Europe have clearly not been persuaded by the putative physiological benefits of the PFS, reduced pulmonary barotrauma, improved tissue perfusion, and early renal function. ${ }^{12}$ Interestingly, only one WE respondent recorded a bad experience with PFS. The reservations of EE surgeons seem to be more due to economic constraints than lack of confidence in the device. Finally, fashioning a custom-made silo was a more popular choice in Europe (19\% of respondents) rather than in the United Kingdom, where it was used in $11 \%$ of the cases. ${ }^{4}$

The best management for an associated intestinal atresia in infants with gastroschisis is still controversial and is usually determined by surgeon preference and condition of the bowel. In this European survey, the option of immediate resection and anastomosis seems to be the most popular, although EE surgeons also favor primary closure and delayed surgery in a similar proportion. Stoma creation either immediately or following staged closure does not seem to be a fashionable approach in Europe. This European attitude reflects previous experiences reported in the literature, where patients who underwent primary intestinal anastomosis had fewest complications, shortest parenteral nutrition requirement, and time to establish full enteral feeds, ${ }^{13-15}$ and those who underwent stoma formation were associated with a higher incidence of complications. ${ }^{15,16}$

The ideal route for delivery of parenteral nutrition differed significantly between WE and EE respondents. It is difficult to explain why peripheral long lines are more popular in $\mathrm{WE}$, whereas central lines are more prevalent in EE. At present, there is no evidence in the literature which option to choose but we could speculate economic considerations lie behind this.

The management of associated intestinal dysmotility in gastroschisis is variable amongst the respondents. It is interesting to note that the use of low-dose erythromycin as a prokinetic agent is still very popular among European surgeons, despite the lack of evidence for its efficacy in one of the very few RCTs in this area. ${ }^{1}$

A study of this nature has an inherent weakness; respondents may include surgeons working in the same center. The effect of this potential bias on study outcome depends on the numbers of such surgeons and may also be center-dependent; in some centers the management provided by all surgeons is similar while in others, different consultants within the same unit manage infants independently and in different ways. We have not adjusted for this potential bias on the grounds that the preference of individual surgeons remains a useful measure of the spread of opinion for the questions asked.

In conclusion, this survey reflects the management of gastroschisis across the entire continent of Europe. Despite potential physiological benefits, the philosophy of staged reduction and, specifically, the use of the PFS are relatively uncommon in both the east and the west. With regard to other key areas, however, management strategies between the two groups differ substantially. A formal Europe-wide audit under the auspices of the EUPSA network would confirm whether this survey reflects actual practice. Importantly, it would also ascertain whether any differences in clinical outcome could be attributed to variation in practice.

Acknowledgments

The authors would like to acknowledge Prof. Prem Puri, who kindly facilitated the administration of this survey at the 2011 EUPSA Congress in Barcelona, Spain.

Conflict of Interest

None

\section{References}

1 Curry JI, Lander AD, Stringer MD; BAPS Multicentre Research Committee . A multicenter, randomized, double-blind, placebocontrolled trial of the prokinetic agent erythromycin in the postoperative recovery of infants with gastroschisis. J Pediatr Surg 2004;39(4):565-569

2 Logghe HL, Mason GC, Thornton JG, Stringer MD. A randomized controlled trial of elective preterm delivery of fetuses with gastroschisis. J Pediatr Surg 2005;40(11):1726-1731

3 Pastor AC, Phillips JD, Fenton SJ, et al. Routine use of a SILASTIC spring-loaded silo for infants with gastroschisis: a multicenter randomized controlled trial. J Pediatr Surg 2008;43(10):1807-1812

4 Owen A, Marven S, Johnson P, et al; BAPS-CASS. Gastroschisis: a national cohort study to describe contemporary surgical strategies and outcomes. J Pediatr Surg 2010;45(9):1808-1816 
5 Aldrink JH, Caniano DA, Nwomeh BC. Variability in gastroschisis management: a survey of North American pediatric surgery training programs. J Surg Res 2012;176(1):159-163

6 Bianchi A, Dickson AP. Elective delayed reduction and no anesthesia: 'minimal intervention management' for gastrochisis. J Pediatr Surg 1998;33(9):1338-1340

7 Huang J, Kurkchubasche AG, Carr SR, Wesselhoeft CW Jr, Tracy TF Jr, Luks FL. Benefits of term delivery in infants with antenatally diagnosed gastroschisis. Obstet Gynecol 2002;100(4):695-699

8 Ergün O, Barksdale E, Ergün FS, et al. The timing of delivery of infants with gastroschisis influences outcome. J Pediatr Surg 2005;40(2):424-428

9 Charlesworth P, Njere I, Allotey J, et al. Postnatal outcome in gastroschisis: effect of birth weight and gestational age. J Pediatr Surg 2007;42(5):815-818

10 Sasaki Y, MiyamotoT, Hidaka Y, et al. Three-dimensional magnetic resonance imaging after ultrasonography for assessment of fetal gastroschisis. Magn Reson Imaging 2006;24(2):201-203
11 Tonni G, Pattaccini P, Ventura A, Casadio G, Del Rossi C, Ferrari B. The role of ultrasound and antenatal single-shot fast spin-echo MRI in the evaluation of herniated bowel in case of first trimester ultrasound diagnosis of fetal gastroschisis. Arch Gynecol Obstet 2011;283(4):903-908

12 Allotey J, Davenport M, Njere I, et al. Benefit of preformed silos in the management of gastroschisis. Pediatr Surg Int 2007;23(11): 1065-1069

13 Hoehner JC, Ein SH, Kim PC. Management of gastroschisis with concomitant jejuno-ileal atresia.J Pediatr Surg 1998;33(6):885-888

14 Phillips JD, Raval MV, Redden C, Weiner TM. Gastroschisis, atresia, dysmotility: surgical treatment strategies for a distinct clinical entity. J Pediatr Surg 2008;43(12):2208-2212

15 Kronfli R, Bradnock TJ, Sabharwal A. Intestinal atresia in association with gastroschisis: a 26-year review. Pediatr Surg Int 2010; 26(9):891-894

16 Di Lorenzo M, Yazbeck S, Ducharme JC. Gastroschisis: a 15-year experience. J Pediatr Surg 1987;22(8):710-712 